
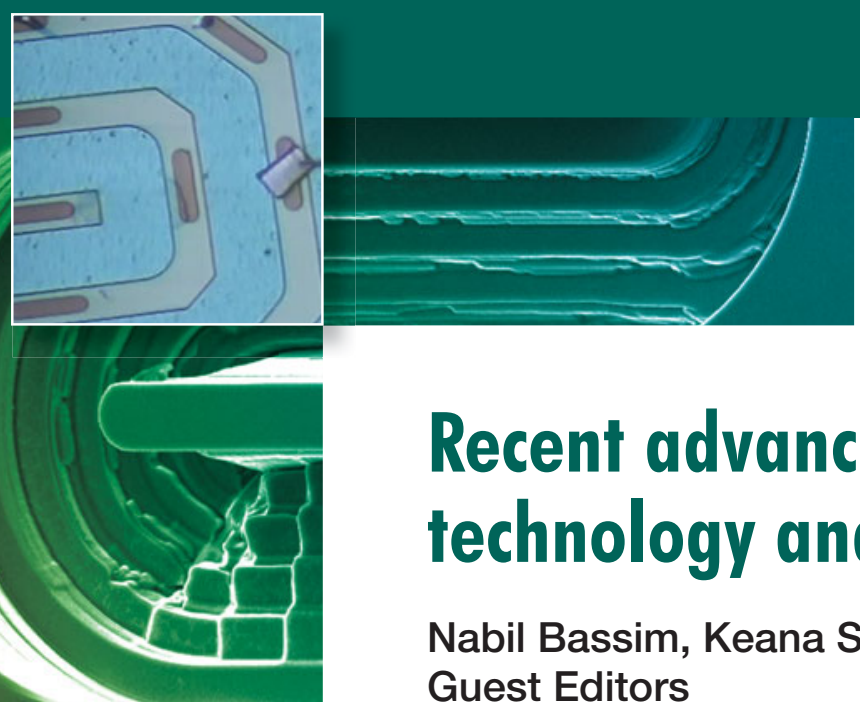

\title{
Recent advances in focused ion beam technology and applications
}

\author{
Nabil Bassim, Keana Scott, and Lucille A. Giannuzzi, \\ Guest Editors
}

\begin{abstract}
Focused ion beam microscopes are extremely versatile and powerful instruments for materials research. These microscopes, when coupled in a system with a scanning electron microscope, offer the opportunity for novel sample imaging, sectioning, specimen preparation, threedimensional (3D) nano- to macroscale tomography, and high resolution rapid prototyping. The ability to characterize and create materials features in a site-specific manner at nanoscale resolution has provided key insights into many materials systems. The advent of novel instrumentation, such as new ion sources that encompass more and more of the periodic table, in situ test harnesses such as cryogenic sample holders for sensitive material analyses, novel detector configurations for 3D structural, chemical, and ion contrast characterization, and robust and versatile process automation capabilities, is an exciting development for many fields of materials research.
\end{abstract}

\section{Introduction}

The focused ion beam (FIB) microscope has been widely used for more than two decades, most significantly in the semiconductor industry but also in various materials science and biomaterials fields. ${ }^{1}$ It generally consists of an ion source, a series of electrostatic lenses to shape the beam, and a scan generator to guide the beam onto a sample with a moving stage. The collision cascade generated by the ion as it interacts with the sample causes sputtering and also generates secondary electrons (SEs) that are gathered by traditional SE detectors. While the contrast attributable to the ion beam is unique, making it sensitive, for example, to phase and grain orientation (see the article by Joy and Michael in this issue), the intuitive image that is formed by an FIB resembles that from a scanning electron microscope (SEM). In addition, the primary energetic ions are much more massive than energetic electrons, providing the ability to sputter material in a site-specific manner that is unique to the FIB. This ability to machine material in a controlled manner with sequential or simultaneous SEM imaging makes the dual platform FIB-SEM a very versatile analytical instrument.

The FIB was first used in the late 1980s by the semiconductor industry for mask repair and circuit edit applications. ${ }^{2,3}$ It achieved widespread use and applications development in the materials and biological sciences when it was coupled with an SEM column onto a dual platform instrument. An example of dual platform geometry is shown in Figure 1. ${ }^{4}$ In a typical dual platform instrument, an electron column is mounted vertically, and the ion column is mounted at an oblique angle $\left(\sim 45^{\circ}\right.$ to $55^{\circ}$ from the vertical). Column positions are reversed in some dual platform instruments. Figure 1a shows a traditional SEM imaging and energy dispersive $\mathrm{x}$-ray spectrometry (EDS) analysis configuration, while Figure $1 \mathrm{~b}$ shows a typical FIB milling configuration where the sample surface is normal to the incident ion beam. By placing the sample at a stage height where the electron beam and the ion beam coincide (as shown in Figure 1 beam traces), FIB processing and SEM characterization processes can be co-localized. In fact, this opened the door to site-specific characterization of materials using electron-induced characteristic x-rays, electron backscattered diffraction, and other electron generated signals that are not directly generated by the ion beam (although small but significant numbers of characteristic $\mathrm{x}$-rays are indeed generated $^{5}$ ). The most widespread application of the FIB-SEM, and one that hastened its rapid development and commercialization, is for creating site-specific scanning transmission electron microscopy (S/TEM) samples for conventional and higher resolution imaging. ${ }^{6-11}$

One of the fastest growing application areas for FIB-SEM in recent years is $3 \mathrm{D}$ imaging and materials analysis. Until recently, 


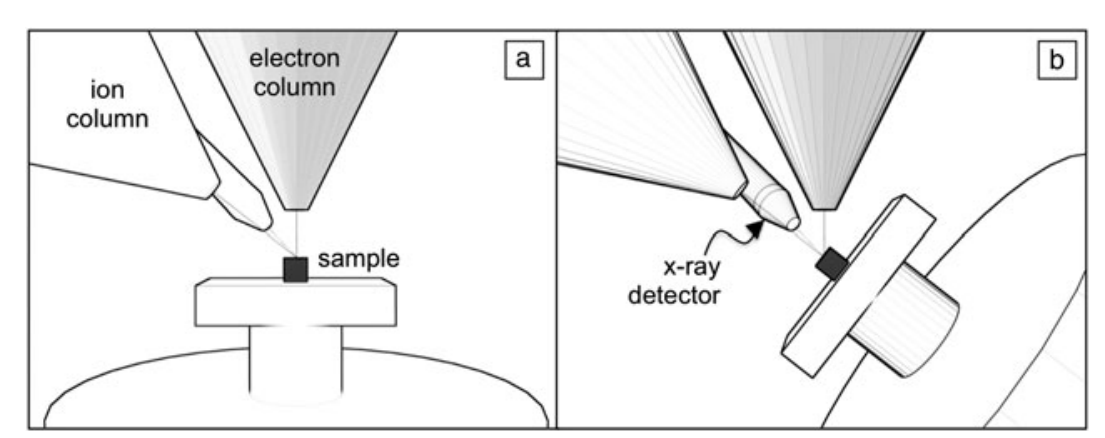

Figure 1. Typical dual platform geometry of a focused ion beam scanning electron microscope (FIB-SEM) instrument. (a) SEM imaging configuration and (b) FIB milling configuration with sample surface normal to the ion beam. FIB-SEM instruments are often equipped with additional analytical detectors such as an X-ray detector, as shown here. Adapted with permission from Reference 4.

is robust and has the advantages of a long source lifetime, stability, low melting point, and reasonably high mass ions for fairly rapid machining. However, there are now several alternative ions available via different sources for FIB microscopes, offering a large range of available ion currents, energies, and beam sizes, leading to important niche applications (see articles by Smith et al. and Joy and Michael in this issue). These include gas field ionization sources (GFIS), ${ }^{22,23}$ which, with $\mathrm{He}^{+}$, can achieve sub-10 nanometer etch lines. ${ }^{24-27}$ Inductively coupled plasma (ICP) ${ }^{28,29}$ sources can achieve a wide range of milling rates using ions from noble gases or other reactive gases. Liquid metal alloy ion sources (LMAISs) ${ }^{30-43}$ operate over a large extent of the periodic table

3D imaging using FIB-SEM was mostly managed with alternating "mill and image" steps set in a repeated loop. The basic processing parameters such as analysis volume dimensions, number of slices, and imaging and milling beam conditions were specified in the beginning of a run and kept constant. More sophisticated 3D materials analysis efforts were driven by individual research groups writing custom instrument control scripts to stitch together sequential milling, imaging, and analysis (x-ray energy dispersive spectrometry [XEDS] or electron backscatter diffraction [EBSD]) steps, ${ }^{12-14}$ sometimes requiring frequent manual interventions. However, these early studies demonstrated the 3D materials analysis potential of FIB-SEM and played a critical role in bringing about the robust and flexible $3 \mathrm{D}$ analytical functionalities in current generation of FIB-SEM instruments. During the past few years, 3D FIB-SEM analysis has been applied to numerous disciplines ranging from fuel cell applications ${ }^{15-17}$ to geology ${ }^{18}$ to life sciences. ${ }^{19}$ Some explore the limits of 3D imaging resolution, while others foray into $3 \mathrm{D}$ analysis combined with in situ probing for dynamic materials property analysis. ${ }^{20}$

The primary goal of this introductory article is to provide key concepts in FIB technology and instrumentation, and to supply sufficient background information to support and frame the six articles in this issue. By providing useful context for the new FIB technologies and FIB-based characterization techniques, this article aims to bridge the gap between FIB methodologies and their implications for advances in materials science, engineering, and design.

\section{Advances in ion sources}

An extremely important development in the past several years is the advent of novel ion sources in commercial FIB instruments, based on a wide variety of technologies. Figure 2 shows the periodic table of the elements highlighting the wide variety of FIB ions that are available either commercially or in the research prototyping phase. ${ }^{21}$ Most commercial FIB microscopes are currently equipped with a liquid metal ion source (LMIS) emitting $\mathrm{Ga}^{+}$ions. $\mathrm{Ga}^{+}$LMIS FIB technology and offer new capabilities for machining and doping at the nanometer scale. Very recently, promising laser-cooled low temperature ion sources (LoTIS) have been developed, making additional elements on the periodic table accessible to FIB technology. ${ }^{44-47}$ GFIS, ICP, and LoTIS are described in the article by Smith et al. in this issue in much further detail, but LMAISs warrant further description here.

Liquid metal ion sources contain a reservoir that holds a metal source. ${ }^{1,48}$ When heated to the liquid phase, the metal flows down a tip (e.g., tungsten needle tip). An extractor voltage is applied to the liquid at the tip that ionizes the droplet. The ions are then accelerated through a column at voltages from $\sim 500 \mathrm{~V}-50 \mathrm{kV}$ and focused using electrostatic lenses. The beam current is selected using apertures and may range from $\sim 1 \mathrm{pA}$ to tens of $\mathrm{nA}$. The small virtual source of $\sim 5 \mathrm{~nm}$ provides for excellent nanometer to micrometer length scale FIB applications. In the case of alloy sources, multiple metals are mixed at their low temperature eutectic composition so that a liquid phase is easily attainable. After heating and extraction, a Wien mass filter is used to separate the different metals based on mass, charge state, and metal clustering. ${ }^{1,49}$ LMAISs are very promising sources for many applications, including site-specific ion implantation ${ }^{50}$ and nanoscale reactions. ${ }^{42}$ After Wien filtering, the available ion current from an LMAIS is always somewhat less compared to an LMIS.

Ion sources, coupled with further advances in instrumentation, enable novel materials devices and design, with either deliberately non-reactive (noble gases) or reactive doping, at nanometer length scales. Ion sources may be further coupled with chemical gas precursors that enable beam-associated deposition and etching within the FIB to produce new lithographic geometries and unique materials. This will be described further in the direct-write lithography article by Ocola et al. in this issue.

Figure 3 shows a graph of beam size versus beam current, which summarizes the source characteristics and optimal uses for a variety of FIB sources discussed in this issue. These data assume the same FIB column type is used for all sources. 

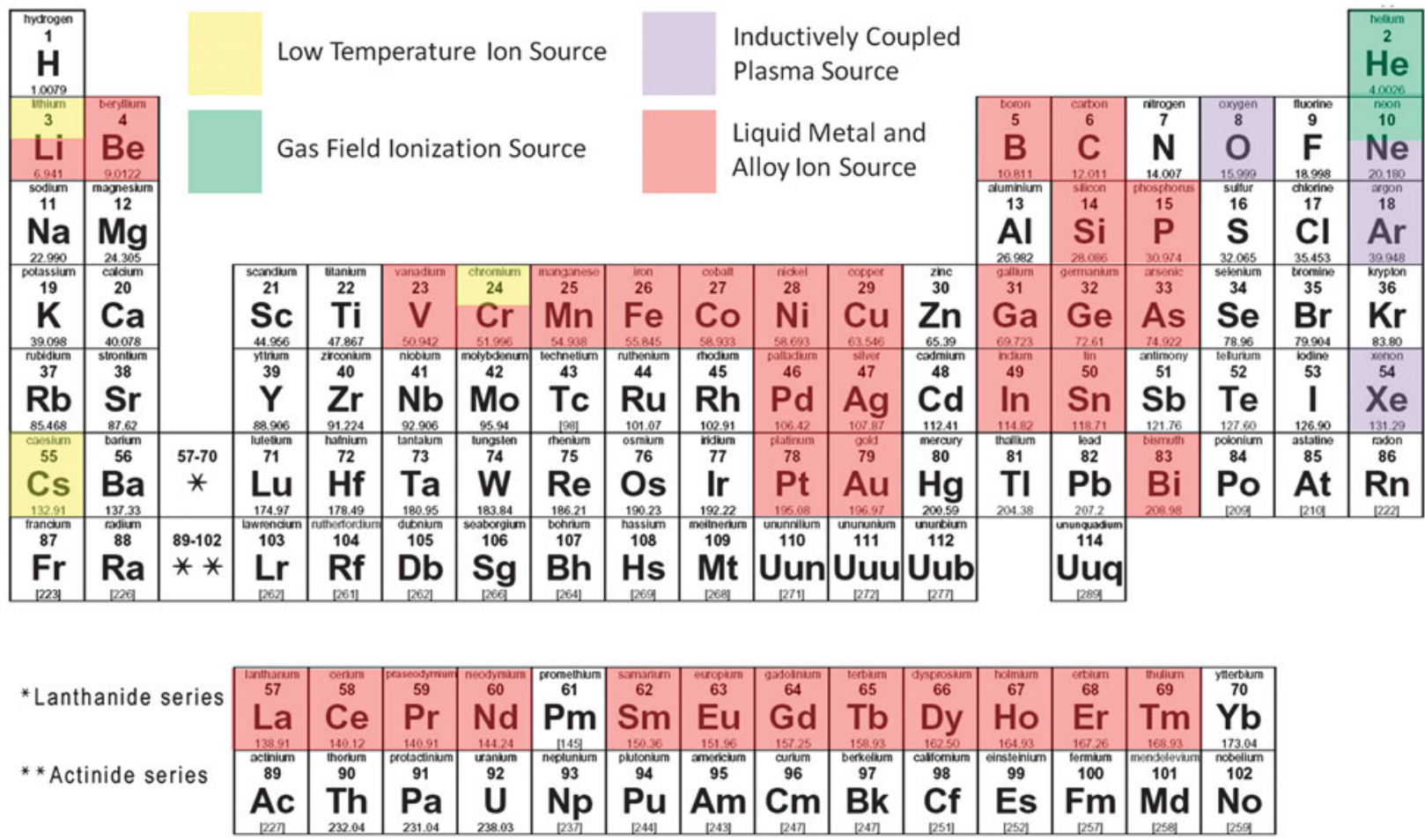

Figure 2. Current and development-phase ion sources by various source technologies encompass a substantial part of the periodic table.

The GFIS (combined with low mass ions) yields a small virtual ion beam diameter that correlates with excellent imaging and nanoscale milling and deposition characteristics. The $\mathrm{Ga}^{+}$ LMIS source is a workhorse source that provides good imaging as well as nano- and micro-milling and deposition characteristics. At larger beam currents, sources with a small virtual ion beam diameter (i.e., GFIS and LMIS) suffer from spherical aberration effects that limit their usefulness for some micro- and macromilling and deposition. The ICP (and electron impact ${ }^{51,52}$ )

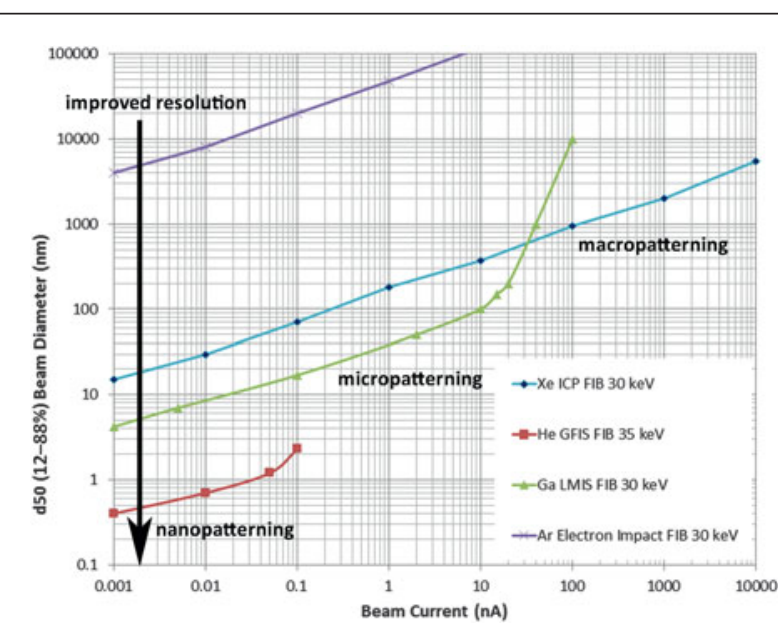

Figure 3. Beam size versus beam current graph of ions from different ion sources. Adapted from data courtesy of Noel Smith, personal communication. sources offer smaller beam sizes at larger ion currents (i.e., better current density) compared to GFIS and LMIS and excel in the macro-length scale. The range of ions/sources commercially available enables milling and imaging at length scales over several orders of magnitude ( $1 \mathrm{~nm}$ to $1 \mathrm{~mm}$ ).

\section{Ion-solid interactions}

To achieve the potential of FIB microscopy, a more thorough understanding of ion-solid interactions is necessary. Ion-solid interactions govern sputtering, redeposition, ion-induced deposition, image resolution, and contrast mechanisms. ${ }^{53}$ The most common ions that are used in commercial FIB instruments are, in order of increasing mass, $\mathrm{He}^{+}, \mathrm{Ne}^{+}, \mathrm{Ar}^{+}, \mathrm{Ga}^{+}$, and $\mathrm{Xe}^{+}$. The stopping and range of ions in matter (SRIM) ${ }^{54-56}$ Monte Carlo simulations of ion trajectories and collision cascades of each of these $30 \mathrm{keV}$ ions impinging into $\mathrm{Si}$ at normal $\left(0^{\circ}\right)$ incident angle are shown in Figure 4. At $30 \mathrm{keV}$, electronic stopping dominates the light mass ions (particularly $\mathrm{He}^{+}$), while nuclear stopping dominates the heavy mass ions. Thus, as seen in Figure 4, the ion range decreases, and the sputter yield increases with an increase in ion mass. $\mathrm{He}^{+}$is unique in that the electronic stopping regime dominates, particularly at the surface, enabling the $\mathrm{He}^{+}$ions to penetrate $\mathrm{Si}$ without much lateral surface straggle and resulting in a sputter yield $<<1$ close to the surface. The lack of $\mathrm{He}^{+}$lateral surface straggle plus the small virtual source contribute to the excellent imaging, nanomilling (particularly for thin films), and nanodeposition resolution. ${ }^{57,58} \mathrm{As} \mathrm{He}^{+}$progresses through the target, it 


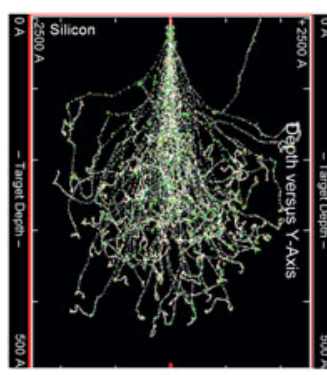

$\mathrm{He}$

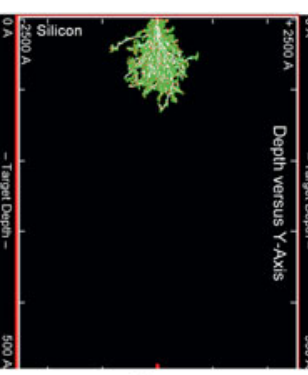

$\mathrm{Ne}$

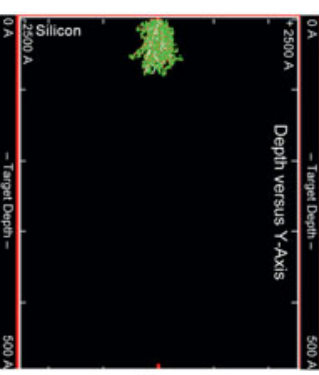

Ar

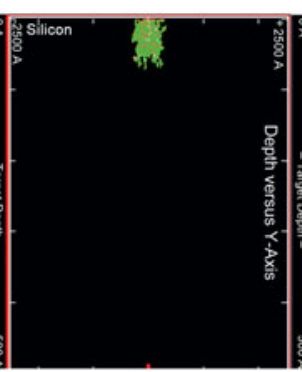

Ga

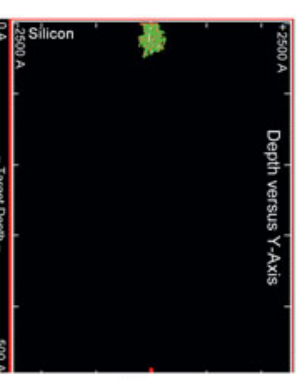

Xe

Figure 4. Stopping and range of ions in matter ion trajectories and recoil motion for $30 \mathrm{keV}$ ions in Si. ${ }^{55}$ The vertical full scale $=500 \mathrm{~nm}$.

loses energy, and the nuclear stopping regime dominates, creating more target recoils and far greater ion straggle far below the surface. Note that the $\mathrm{He}^{+}$ion lateral straggle is far greater than either of the heavier ions shown. As a result, damage via $\mathrm{He}^{+}$ion implantation in bulk materials is dose dependent (and therefore cumulative) and proportional to the distribution of ions below the target surface. ${ }^{59,60}$

\section{Reducing surface damage for specimen preparation}

Energetically implanted ions, as described in the collision cascade outlined in Figure 3, leave a damaged zone under the target area that can alter the chemistry, structure, and mechanical, optical, and electronic properties of a material. Reducing ion implantation damage (and/or in the extreme case amorphization) is important in the sample preparation for quantitative high resolution S/TEM, ${ }^{61,62}$ atom probe tomography, ${ }^{63,64} \mathrm{EBSD},{ }^{65,66}$ and other techniques where surface quality is critical. The technique of reducing surface damage via low energy ion polishing is governed by ion-solid interaction physics, as explained later. ${ }^{67,68}$

Figure 5 shows the longitudinal ion range into $\mathrm{Si}$ at $85^{\circ}$ incident (glancing) angle as a function of ion energy for $\mathrm{He}$, $\mathrm{Ne}, \mathrm{Ar}, \mathrm{Ga}$, and Xe. Note, by convention, incident angle is defined as the angle between the surface normal and the direction of the incoming ion beam. As illustrated, the ion range decreases with a decrease in energy for each ion species. In addition, the heavier the ion mass, the closer to the surface it is stopped, resulting in less surface damage to the target. However, the rate of decrease in ion range increases nonlinearly as the ion energy decreases, particularly for heavy ions such as $\mathrm{Ne}^{+}$, $\mathrm{Ar}^{+}, \mathrm{Ga}^{+}$, and $\mathrm{Xe}^{+}$, and the difference in ion ranges between ion types becomes negligible at low ion energies. This implies that reducing the ion energy is more important than choosing a particular ion type to limit implantation damage. Using $\mathrm{He}^{+}$ions to reduce surface damage is still debatable since at low energy, (1) the range is still fairly large and (2) the sputter yield is $<<1$, resulting in many more ions being implanted than particles being sputtered.

Figure 6 shows a graph of longitudinal ion range as a function of incident angle for $\mathrm{Ga}^{+}$into $\mathrm{Si}$ at $30 \mathrm{keV}, 5 \mathrm{keV}$, and $1 \mathrm{keV}$.
Note that the ion range decreases with an increase in incident angle. This behavior is similar for other ion types. However, the influence of incident angle on the ion range decreases as the ion energy decreases. In particular, there is very little change in ion range with varying incident angle for $1 \mathrm{keV}$ ions. Thus, there is much flexibility in the choice of the incident angle for low energy polishing. It is difficult to form tightly focused low energy ion probes due to chromatic aberrations. Therefore, low energy ion polishing techniques generally rely on FIB imaging of the surface of interest at $<10^{\circ}$ (e.g., $80^{\circ}$ to $89^{\circ}$ incident angle) with contrast conditions that are just "good enough" to position the low energy ions onto the surface of interest. Note that limiting the low energy ions to just the surface of interest reduces the chance for redeposition artifacts. Indeed, low energy $\mathrm{Ga}^{+}, \mathrm{Ar}^{+}$, and $\mathrm{Xe}^{+}$ions have all been shown to reduce surface damage in specimens. ${ }^{69-78}$

Another important consideration, particularly in the FIB modification and preparation of biological and polymeric samples, is the generation and management of heat and radiolysis (or broken bonds in the sample due to inelastic collisions by

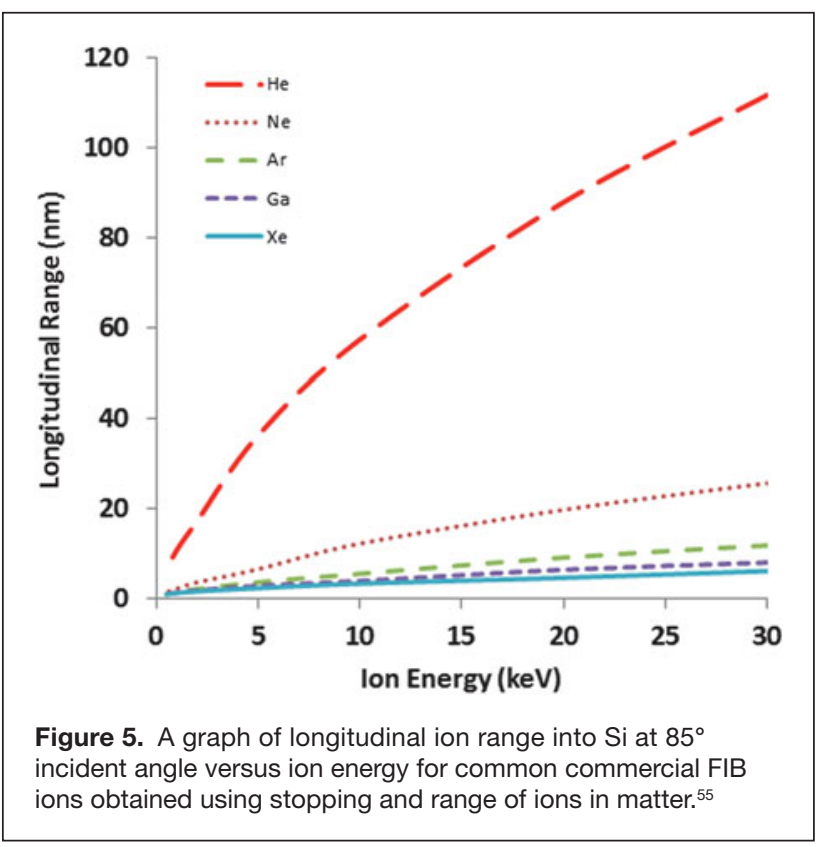




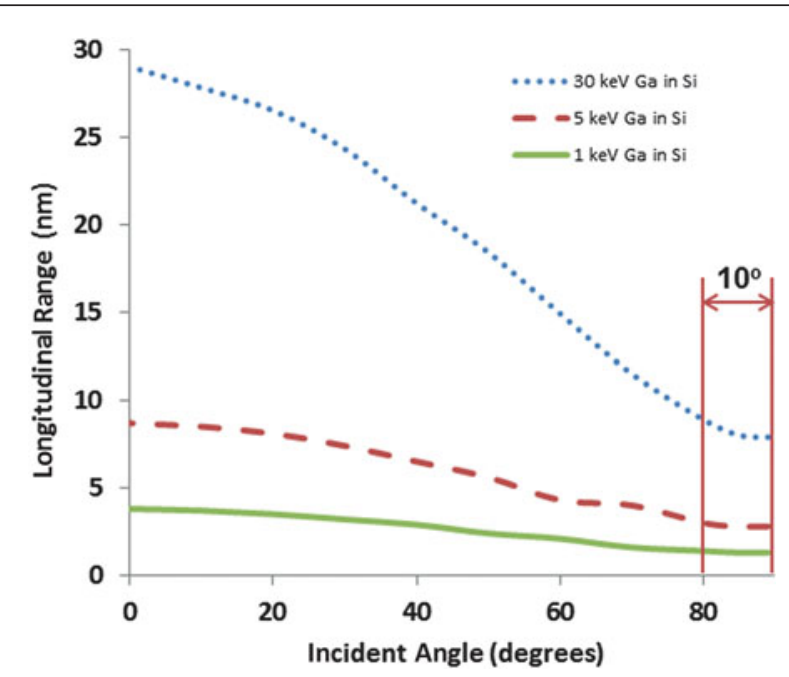

Figure 6. A graph of longitudinal ion range of $\mathrm{Ga}^{+}$into Si versus incident angle for $30 \mathrm{keV}, 5 \mathrm{keV}$, and $1 \mathrm{keV}$ ions from data using the SRIM (stopping and range of ions in matter) simulation software. ${ }^{55}$

ions or ion-generated secondary electrons with the sample) during milling operations. Excessive heat can lead to phase and chemical changes and mechanical weakening during milling. Mitigation strategies include the use of low beam currents, ${ }^{79}$ changes in beam overlap during milling, ${ }^{80}$ and use of mechanically supportive frames to maintain mechanical rigidity. ${ }^{81}$ It was also shown that electron beam imaging during preparation of soft materials may chemically modify the structures. ${ }^{81}$

\section{Applications \\ Recent advances in S/TEM specimen preparation}

The basics of FIB specimen preparation methods for S/TEM analysis are fairly mature and have been described in detail elsewhere and are illustrative of the power of the FIB-SEM. ${ }^{82-85}$ These basic techniques have also been used for site-specific specimen preparation for surface science studies, atom probe tomography, and other analytical instruments. ${ }^{63,86} \mathrm{~A}$ site of interest is identified and protected using deposition and the imaging capabilities of either the FIB and/or the SEM. (There are numerous other protective cap layers that can be used prior to insertion in the FIB-SEM.) The FIB is used to incrementally mill away all but the region of interest by stepping through smaller and smaller beam currents (i.e., beam diameters) as the region of interest is approached. These same techniques have been used to create electron transparent specimens using a $\mathrm{Xe}^{+}$ ICP FIB. ${ }^{69}$

For conventional S/TEM, the specimen can be milled to electron transparency $(\sim 100$ $\mathrm{nm}$ to $500 \mathrm{~nm}$ ) using the fine probes available with high energy (e.g., $30 \mathrm{keV}$ ) ions. When thinner specimens are needed for high resolution
$\mathrm{S} / \mathrm{TEM}$ or when surface damage must be minimized, the specimen is FIB milled to a thickness of $\sim 200 \mathrm{~nm}$ to $1 \mu \mathrm{m}$ using a high energy beam and then further ion milled in one or more lower ion energy settings (typically $5 \mathrm{keV}$ and $2 \mathrm{keV}$ ). Low energy milling simultaneously thins the specimen and reduces the ion implantation/amorphization damage with each energy step. Understanding the ion-solid interactions described previously is critical for developing suitable specimens for analysis by aberration-corrected S/TEM and to achieve atomic resolution imaging, XEDS, and electron energy loss spectroscopy (EELS) fine structure.

FIB specimen preparation methods may be broadly categorized as either lift-out or non-lift-out types. In non-lift-out types, the region of interest is pre-thinned by any number of techniques (e.g., tripod polishing, small angle cleavage technique) and then adhered to a suitable grid or carrier for subsequent FIB milling followed by S/TEM. ${ }^{9,87-92}$ While this negates the need for a lift-out probe and generally reduces FIB time required for final milling, more time is spent up front on initial sample preparation. The lift-out methods, described in detail elsewhere, ${ }^{93,94}$ may be generally referred to as either ex situ lift-out (EXLO) or in situ lift-out (INLO), depending on whether manipulation of the site of interest to a suitable grid or carrier is performed outside (ex situ) or inside (in situ) the FIB instrument.

Conventional EXLO and manipulation to a carbon coated grid (as shown in Figure 7a) is a well-known method for its ease, speed, and reproducibility. ${ }^{93}$ EXLO is also appropriate where manipulation of an electron transparent specimen to an S/TEM microelectromechanical system carrier device is required (as shown in Figure $7 b$ ), since this avoids the FIB imaging and potential ion implantation damage that can occur to the specimen during INLO. Recent advances in EXLO include a new grid design and method that negates the need for a carbon film and allows for further FIB milling or other processing after lift-out. ${ }^{95-97}$ An electron transparent or thicker specimen is lifted out and manipulated to a slotted S/TEM grid surface such that the specimen may be directly analyzed and/or FIB milled or processed as shown in Figure 7c. Thick specimens can be easily and directly manipulated into a backside orientation, and when further FIB-milled, curtaining artifacts are reduced or eliminated. ${ }^{95}$ EXLO is a flexible, fast, and a 
reproducible technique that can save labor and FIB instrumentation time, ultimately reducing the cost per specimen.

Another advance in S/TEM sample preparation is the " $X$ " or "X2" method, which yields large thin areas by FIB milling each side of the specimen from two different angles, resulting in a projected shape of the letter "X." ${ }^{98-100}$ The intersection of each FIB cross cut in the center of the projected " $\mathrm{X}$ " yields the thinnest region of the specimen and is supported on all sides by the surrounding thicker portion of the specimen. For soft or hydrated materials TEM specimen preparation, several novel cryogenic specimen preparation techniques have been developed, ${ }^{101-103}$ often accompanied with methods to ensure mechanical stability of the thinned specimen. Since prolonged exposure to electron beams can modify the chemical structure of a soft material specimen, ${ }^{79-81}$ efforts should be made to minimize electron (as well as ion) beam exposure during thinning.

\section{Direct-write lithography}

FIBs can sculpt materials over a wide range of length scales (e.g., nm to tens of $\mu \mathrm{m}$ ), hence FIB instruments are ideal for rapid-prototyping applications. They are useful for applications such as circuit-edit in high aspect ratio vias, ${ }^{104}$ development of photonic, ${ }^{105}$ plasmonic, ${ }^{106}$ and microfluidic ${ }^{107}$ structures, and for providing site-specific implanted seeds for growth of quantum dots. ${ }^{108}$ Their use spans from milling ribbons in graphene ${ }^{24}$ up to fabrication of large-scale Fresnel zone plates. ${ }^{109}$ The recent incorporation of excimer lasers into FIB-SEM systems offers the possibility of material removal and patterning on yet larger length scales. ${ }^{110}$ The FIB can also perform single pass 3D subtractive lithography. When coupled with precursor gases, high-aspect ratio trenches (e.g., 20:1) and complex graded-depth structures are possible. 3D capability at this resolution is currently not duplicated by electron-beam lithography or optical lithography, whose resolution is diffraction limited.

With the continual development of beam-dissociated metal-organic precursors, FIB is capable of fabricating metallic and insulator structures (as opposed to two-photon polymerization $^{111}$ ) in an additive fashion as well. While the speed of this fabrication is not as high as laser chemical vapor deposition for large-scale circuit repair, FIB certainly has a niche for prototyping novel experimental structures that are unobtainable through other methods and can later be scaled using other techniques. Since FIB lithography is a serial process, the slow writing speed limits its use in large-scale manufacturing, although there have been strong efforts in developing multibeam lithography systems using ion projection through apertures. $^{112}$

\section{D analysis}

The basic approach to 3D FIB-SEM analysis is simple. For an excellent overview of this analysis process, Cantoni and Holzer's review of FIB tomography is recommended. ${ }^{113}$ Briefly, once a volume of interest (VOI) has been identified, a protective layer (e.g., most commonly of Pt or C) is ion deposited on the top surface of the VOI to smooth out the surface roughness and/or to protect the VOI from ion beam damage. Material surrounding the VOI is then removed to minimize obstruction due to the redeposition of the sputtered material. For freestanding features or particles, this removal step is obviously not needed, although for brittle or highly porous material, encasing the particles in a $\mathrm{Pt}$ or $\mathrm{C}$ layer can provide structural support. Once the VOI is prepared, the initial analysis surface is imaged and/or analyzed using appropriate analytical techniques such as XEDS or EBSD ${ }^{4,114-116}$ (see the article by Kotula et al. in this issue for further details). Another layer of material is then removed from the analysis surface, and the labile surface is imaged and analyzed again. This mill-image-analyze process is repeated until the VOI is exhausted or the available FIB time runs out.

Some of the main challenges for 3D FIB-SEM analysis can be broadly categorized into the following areas:

- Hardware limitations such as beam stability and detector performances.

- Software limitations such as availability of robust and flexible automated control software.

- Work-flow issues such as sample preparation, VOI identification, and use of correlative techniques.

- Data processing and interpretation challenges.

As discussed in Cantoni and Holzer's article in this issue, recent advances in FIB and SEM columns as well as imaging detector technology have addressed many of the earlier hardware and software related challenges, vastly improving the quality of 3D FIB-SEM datasets obtained today when compared to what was possible just a few years previously. Simultaneous or sequential milling and imaging approaches using smart acquisition algorithms can significantly reduce the overall data acquisition time, while the use of multiple detectors or detector modes can reduce some of the problematic data interpretation challenges. ${ }^{117}$ Narayan et al. recently presented 3D correlative FIB analysis of HIV infected cells where they applied a multi-resolution imaging strategy to capture relevant details (HIV cores) at a very high resolution $(3 \mathrm{~nm} \times 3 \mathrm{~nm} \times 3 \mathrm{~nm}$ voxel), while contextual information (cellular structures) was captured at lower resolutions. ${ }^{118}$ Effective use of correlative techniques has enabled precise localization of VOIs, as demonstrated by Narayan et al. ${ }^{118}$ and Maco et al. ${ }^{119}$

Another challenging aspect of $3 \mathrm{D}$ analysis is striking the optimal balance between mutually conflicting experimental conditions needed for milling, imaging, and spectral analysis without introducing artifacts or damage. 3D analysis is increasingly being applied to biological and "soft" polymeric materials. ${ }^{120-124}$ For these materials, prolonged exposure to the electron beam can cause significant artifacts. ${ }^{4,79-81}$ Additionally, most analytical methods require high energy and high current electron beam conditions for adequate signal-to-noise acquisition and analysis. However, the electron range and subsequent signals generated from electron beam-solid interactions is inversely proportional to the atomic number $(Z)$ of the constituent elements. Thus, signals generated from distances larger 
than an FIB milled slice can result in unexpected imaging artifacts, especially when combined with 3D FIB tomography. ${ }^{125}$ Even with recent advances in detector technologies, ${ }^{126-129}$ an incident beam energy of $5 \mathrm{keV}$ to $20 \mathrm{keV}$ is preferred for analytical measurements, while $1 \mathrm{keV}$ to $2 \mathrm{keV}$ is preferred for imaging soft materials. Although high solid angle detectors or multi-detector configurations can help with the signal-to-noise problem, many of these solutions do not work well with existing mill and image approaches. Advances in beam deceleration or stage biasing can further improve imaging conditions by providing high brightness while reducing sample damage and enhancing surface sensitivity. ${ }^{130-133}$

\section{Current challenges and future directions for 3D analysis}

With the increased use of nanomaterials in many application areas, the ability to analyze and characterize materials and systems at the nanoscale has become critical. However, to understand how the nanomaterials and nanoscale features affect bulk material properties, macro- to micro- to nanoscale correlative material information is essential. The simplest solution would be a brute force approach, where the highest resolution information is collected from the entire material volume of interest. This method is obviously not very scalable. One possible approach is multi-resolution analysis similar to that presented by Narayan et al. ${ }^{118}$ In this case, a priori knowledge of the HIV core locations obtained from fluorescence imaging was used to specify areas of high resolution imaging. However, borrowing from the remote sensing and machine vision communities, ${ }^{134-136}$ some form of active or adaptive multi-resolution image acquisition strategy could also be devised, enabling real-time determination of required imaging conditions based on the information content of the most recent image frames. Such dynamic, datadriven experimental control approaches could simultaneously accommodate large volume, high resolution (where needed), and rapid analysis requirements. Another intriguing option is the use of compressive sensing for FIB-SEM imaging and analysis. Compressive sensing is a new and novel approach where incomplete sampling under certain circumstances can be used to accurately recover the full dataset. ${ }^{137-140}$ Application of the compressive sensing method is most active in the medical imaging field, ${ }^{141,142}$ although it has also been successfully applied to STEM tomography. ${ }^{143}$

As the demand for high resolution, high content imaging increases, the cost and challenges of acquiring, storing, processing, and analyzing today's very large 3D imaging datasets are increasing even more rapidly. The most interesting and informative datasets are often left uncollected, unprocessed, and unexamined because there is not sufficient time or resources. We expect that effective use of novel computational and data informatics methods will become a critical component of 3D FIB-SEM analysis.

\section{In situ analysis}

Site-specific materials modification capability of the FIB-SEM has enabled a plethora of interesting in situ experiments for materials characterization. FIB-SEM has been coupled with a variety of analytical and materials processing techniques in recent years. Examples include cathodoluminescence, ${ }^{14,145}$ secondary ion mass spectrometry, ${ }^{146,147}$ and laser ablation. ${ }^{148}$ Many custom stages and sample holders have also been developed for electronic, mechanical, and chemical characterization. ${ }^{149-153}$ Antoniou et al.'s article in this issue presents several of these novel in situ FIB analysis techniques.

\section{In this issue}

The articles in this issue discuss aspects of FIB technology and applications that have been evolving very rapidly. The article by Smith et al. discusses recent advances in ion sources beyond the standard $\mathrm{Ga}^{+}$ion source. The GFIS and ICPSbased FIB instrumentation has matured and complements the performance envelope of LMIS FIBs. Exciting new source technologies such as LoTIS are also emerging with promises of interesting imaging and material modification options. The article by Ocola et al. discusses direct-write nanofabrication in all three dimensions using advanced beam control capabilities, novel high-resolution sources, and novel etch chemistries. The article by Joy and Michael provides insights into ion-induced secondary electron image interpretation, including materials and channeling contrast. High-resolution dynamic monitoring coupled with custom probing enables novel in situ characterization approaches, and Antoniou et al. present several examples in their article. 3D characterization capabilities have improved vastly since the last reviews of FIB technology, including in MRS Bulletin. ${ }^{14,115}$ Two articles in this issue are dedicated to an increasingly important application of 3D FIB-SEM. The one by Cantoni and Holzer presents techniques and experimental conditions required for acquiring 3D FIB-SEM datasets, while the article by Kotula et al. discusses hyperspectral image data processing and quantification strategies of 3D FIB-SEM datasets. This issue of MRS Bulletin is intended to inform readers about the state of the art of FIB technology and its applications in materials research, and it provides insights into the future potential for materials characterization and processing using FIBs.

\section{Disclaimer}

Commercial materials identified in this article are not intended to imply recommendation or endorsement by the National Institute of Standards and Technology, nor is the intention of this article to imply that the materials identified are necessarily the best available for the purpose.

\section{References}

1. J. Orloff, Rev. Sci. Instrum. 64, 1105 (1993).

2. J. Melngailis, J. Vac. Sci. Technol. B 5, 469 (1987).

3. M.W. Phaneuf, Micron 30, 277 (1999).

4. K. Scott, J. Microsc. 242, 86 (2010).

5. L.A. Giannuzzi, B.P. Gorman, J. Vac. Sci. Technol. A 27, 668 (2009).

6. E.C.G. Kirk, D.A. Williams, H. Ahmed, Inst. Phys. Conf. Ser. 100, 501 (1989).

7. R.J. Young, E.C.G. Kirk, D.A. Williams, H. Ahmed, in Mater. Res. Soc. Symp. Proc. 199 (Materials Research Society, Warrendale, PA, 1990), p. 205.

8. D.P. Basile, R. Boylan, B. Baker, K. Hayes, D. Soza, in Mater. Res. Soc. Symp. Proc. 254 (Materials Research Society, Warrendale, PA, 1992), p. 23. 
9. K. Park, in Mater. Res. Soc. Symp. Proc. 199 (Materials Research Society, Warrendale, PA, 1990), p. 271

10. M.H.F. Overwijk, F.C. van den Heuvel, C.W.T. Bulle-Lieuwma, J. Vac. Sci. Technol. B 11, 2021 (1993)

11. L.A. Giannuzzi, J.L. Drown, S.R. Brown, R.B. Irwin, F.A. Stevie, in Mater. Res. Soc. Symp. Proc. 480, R.M. Anderson, S.D. Walch, Eds. (Materials Research Society, Warrendale, PA, 1997), p. 19.

12. M.D. Uchic, L. Holzer, B.J. Inkson, E.L. Principe, P. Munroe, MRS Bull. 32 408 (2007)

13. M.D. Uchic, M.A. Groeber, D.M. Dimiduk, J.P. Simmons, Scripta Mater. $\mathbf{5 5}$, 23 (2006).

14. P.G. Kotula, M.R. Keenan, J.R. Michael, Microsc. Microanal. 12, 36 (2006) 15. D. Gostovic, J.R. Smith, D. Kundinger, K.S. Jones, E.D. Wachsman, Electrochem. Solid-State Lett. 10, B214 (2007)

16. P.R. Shearing, Q. Cai, J.I. Golbert, V. Yufit, C.S. Adjiman, N.P. Brandon, J. Power Sources 195, 4804 (2010)

17. J. Joos, M. Ender, I. Rotscholl, N.H. Menzler, E. Ivers-Tifféea, J. Power Sources 246, 819 (2014).

18. R. Wirth, Chem. Geol. 261, 217 (2009)

19. G. Knott, H. Marchman, D. Wall, B. Lich, J. Neurosci. 28, 2959 (2008)

20. L.D. Menard, J.M. Ramsey, Nano Lett. 11, 512 (2011).

21. A.D. Wieck; http://www.ruhr-uni-bochum.de/afp/downloads/ausstattung/ ionen.pdf

22. R.H. Livengood, S. Tan, R. Hallstein, J. Notte, S. McVey, F.H.M. Faridur Rahman, Nucl. Instrum. Methods Phys. Res. A 645, 136 (2011).

23. L. Scipioni, L.A. Stern, J. Notte, S. Sibrandij, Adv. Mater. Proc. 166, 27 (2008).

24. M.C. Lemme, D.C. Bell, J.R. Williams, L.A. Stern, B.W.H. Baugher, P. JarilloHerrero, C.M. Marcus, ACS Nano 3, 2674 (2009).

25. V. Sidorkin, E. van Veldhoven, E. van der Drift, P. Alkemade, H. Salemink, D. Maas, J. Vac Sci. Technol. B 27, L18 (2009).

26. J. Yang, D.C. Ferranti, L.A. Stern, C.A. Sanford, J. Huang, Z. Ren, L. Qin, A.R. Hall, Nanotechnology 22, 285310 (2011).

27. W.-D. Li, W. Wu, R.S. Williams, J. Vac. Sci. Technol. B 30, 06F304-1 (2012). 28. N.S. Smith, W.P. Skoczylas, S.M. Kellogg, D.E. Kinion, P.P. Tesch, O. Sutherland, A. Aanesland, R.W. Bowell, J. Vac. Sci. Technol. B 24, 2902 (2006).

29. N.S. Smith, D.E. Kinion, P.P. Tesch, R.W. Boswell, Microsc. Microanal. 13 (Suppl. 2), 180 (2007).

30. L. Bischoff, Nucl. Instrum. Methods Phys. Res. B 266, 1846 (2008).

31. L. Bischoff, Ultramicroscopy 103, 59 (2005).

32. L. Bischoff, C. Akhmadaliev, J. Phys. D Appl. Phys. 41, 052001 (2008).

33. L. Bischoff, G.L. Mair, C.J. Aidinis, C.A. Londos, C. Akhmadaliev, T. Ganetsos, Ultramicroscopy 100, 1 (2004).

34. L. Bischoff, G.L.R. Mair, A.W.R. Mair, T. Ganetsos, C. Akhmadaliev, Nucl. Instrum. Methods Phys. Res. B 222, 622 (2004).

35. L. Bischoff, W. Pilz, T. Ganetsos, R.G. Forbes, C. Akhmadaliev, Ultramicroscopy 107, 865 (2007)

36. L. Bischoff, W. Pilz, P. Mazarov, A.D. Wieck, Appl. Phys. A 99, 145 (2010). 37. T. Ganetsos, G.L.R. Mair, C.J. Aidinis, L. Bischoff, Physica B Condens. Matter 340, 1166 (2003)

38. T. Ganetsos, G.L.R. Mair, L. Bischoff, J. Teichert, D. Kioussis, Solid State Electron. 45, 1049 (2001)

39. P. Mazarov, A.D. Wieck, L. Bischoff, W. Pilz, J. Vac. Sci. Technol. B 27, L47 (2009).

40. S. Bauerdick, L. Bruchhaus, P. Mazarov, A. Nadzeyka, R. Jede, J. Fridmann, J.E. Sanabia, B. Gila, B.R. Appleton, J. Vac. Sci. Technol. B31, 06F404-1 (2013). 41. P. Mazarov, A. Melnikov, R. Wernhardt, A.D. Wieck, Appl. Surf. Sci. 254, 7401 (2008).

42. M. Aouassa, A. Ronda, L. Favre, A. Delobbe, P. Sudraud, I. Berbezier, J. Appl. Phys. 114, 034301 (2013)

43. A. Benkouider, I. Berbezier, A. Ronda, L. Favre, E.R. Gomes, I.C. Marcus, I. Alonso, A. Delobbe, P. Sudraud, Thin Solid Films 543, 69 (2013).

44. B. Knuffman, A.V. Steele, J.J. McClelland, J. Appl. Phys. 114, 044303 (2013). 45. B. Knuffman, A.V. Steele, J. Orloff, J.J. McClelland, New J. Phys. 13, 103035 (2011).

46. A.V. Steele, B. Knuffman, J.J. McClelland, J. Orloff, J. Vac. Sci. Technol. B 28, C6F1 (2010).

47. J.L. Hanssen, S.B. Hill, J. Orloff, J.J. McClelland, Nano Lett. 8, 2844 (2008). 48. L.W. Swanson, Nucl. Instrum. Methods Phys. Res. 218, 347 (1983)

49. T. Shiokawa, P.H. Kim, K. Toyoda, S. Namba, T. Matsui, K. Gamo, J. Vac. Sci. Technol. B1,1117 (1983).

50. M. Lemaitre, S. Tongay, X. Wang, D.K. Venkatachalam, J. Fridmann, B.P. Gila, F. Arthur, F. Ren, R.G. Elliman, B.R. Appleton, Appl. Phys. Lett. 100, 193105 (2012)

51. A.O. Nier, Rev. Sci. Instrum. 18, 398 (1947).

52. J. Schwieters, H.G. Crammer, T. Heller, U. Jurgens, E. Niehuis, J. Zehnpfenning,

A.J. Benninghoven, J. Vac. Sci. Technol. A 9, 2864 (1991).
53. L.A. Giannuzzi, B.I. Prenitzer, B. Kempshall, in Introduction to Focused Ion Beams, L.A. Giannuzzi, F.A. Stevie, Eds. (Springer, New York, 2005), pp. 13-52. 54. J.F. Ziegler, Nucl. Instrum. Methods Phys. Res. B, 219-220, 1027 (2004). 55. J.F. Ziegler, SRIM; www.srim.org.

56. J.F. Ziegler, J.P. Biersack, U. Littmark, The Stopping Range of lons in Solids (Pergamon Press, New York, 1996)

57. M. Ananth, L. Stern, D. Ferranti, C. Huynh, J. Notte, L. Scipioni, C. Sanford, B. Thompson, in Proc. SPIE 8036, 80360M (2011).

58. M. Ananth, L. Stern, J. Notte, L. Scipioni, C. Huynh, D. Ferranti, in Proc. 15th European Congress on Microscopy EMC (2012).

59. R. Livengood, S. Tan, Y Greenzweig, J. Notte, S. McVey, J. Vac. Sci. Technol. B, 273244 (2009)

60. L.A. Giannuzzi, Microsc. Microanal. 19 (S2), 358 (2013).

61. L.A. Giannuzzi, R. Guerts, J. Ringnalda, Microsc. Microanal, 11 (Suppl. 2), 828 (2005)

62. A. Gozar, G. Logvenov, L. Fitting Kourkoutis, A.T. Bollinger, L.A. Giannuzzi, D.A. Muller, I. Bozovic, Nature 455, 782 (2008).

63. K. Thompson, D. Lawrence, D.J. Larson, J.D. Olson, T.F. Kelly, B. Gorman, Ultramicroscopy 107, 131 (2007)

64. M. Miller, K.F. Russell, K. Thompson, R. Alvis, D.J. Larson, Microsc. Microanal. 13, 428 (2007).

65. T.L. Matteson, S.W. Schwarz, E.C. Houge, B. Kempshall, L.A. Giannuzzi, J. Electron. Mater. 31, 33 (2002).

66. J.R. Michael, L.A. Giannuzzi, Microsc. Microanal. 13 (Suppl. 2), 926 (2007). 67. M. Natasi, J.W. Mayer, J.K. Hiryonen, Ion-Solid Interactions: Fundamentals and Applications (Cambridge University Press, New York, 1996) pp. 133-139.

68. B.I. Prenitzer, C.A. Urbanik-Shannon, L.A. Giannuzzi, S.R. Brown, R.B. Irwin, T.I. Shofner, F.A. Stevie, Microsc. Microanal. 9, 216 (2003).

69. L.A. Giannuzzi, N.S. Smith, Microsc. Microanal. 19 (Suppl. 2), 646 (2001). 70. H. Sasaki, T. Matsuda, T. Kato, T. Muroga, Y. lijima, T. Saitoh, F. Iwase, Y. Yamada, T. Izumi, Y. Shiohar, T. Hirayama, J. Electron Microsc. 53, 497 (2004). 71. L.A. Giannuzzi, Microsc. Microanal. 11 (Suppl. 2), 828 (2005)

72. S. Sadayama, H. Takahashi, K. Iwasaki, T. Fujii, Microsc. Microanal. 12 (Suppl. 2), 1298 (2006).

73. L.A. Giannuzzi, B. Van Leer, J. Ringnalda, Microsc. Microanal. 13 (Suppl. 2) $1516(2007)$

74. S. Bals, W. Tirry, R. Geurts, Z. Yang, D. Schryvers, Microsc. Microanal. 13, 80 (2007).

75. A. Genc, D.P. Basile, G.B. Viswanathan, H.L. Fraser, P. Fischione, Microsc Micronanal. 13 (Suppl. 2), 1520 (2007).

76. J.R. Michael, P.G. Kotula, Microsc. Microanal. 14 (Suppl. 2), 976 (2008)

77. L.A. Giannuzzi, N.S. Smith, Microsc. Microanal. 17 (Suppl. 2), 646 (2011).

78. R.D. Kelly, K. Song, B. Van Leer, D. Wall, L. Kwakman, Microsc. Microanal. 19 (Suppl. 2), 862 (2013).

79. S. Kim, M.J. Park, N.P. Balsara, G. Liu, A.M. Minor, Ultramicroscopy 111 191 (2011).

80. B.P. Gorman, L. Sahu, A. Shaito, D. Nandika, O. Olea-Mejia, W. Brostow, Microsc. Microanal. 12 (Suppl. 2), 1000 (2006).

81. N.D. Bassim, B.T. De Gregorio, A.D.L. Kilcoyne, K. Scott, T. Chou, S. Sirick, G. Cody, R.M. Stroud, J. Microsc. 245, 288 (2012).

82. L.A. Giannuzzi, F.A. Stevie, Micron 30, 197 (1999).

83. J. Li, T. Malis, S. Dionne, Mater. Charact. 57, 64 (2006)

84. J. Mayer, L.A. Giannuzzi, T. Kamino, J. Michael, MRS Bull. 32, 400 (2007)

85. R. Anderson, S.J. Klepeis, in Introduction to Focused Ion Beams, L.A. Giannuzzi, F.A. Stevie, Eds. (Springer, New York, 2005) pp. 173-246.

86. F.A. Stevie, C.B. Vartuli, L.A. Giannuzzi, T.L. Shofner, S.R. Brown, B. Rossie, F. Hillion, R.H. Mills, M. Antonell, R.B. Irwin, B.M. Purcell, Surf. Interface Anal. 31, 345 (2001)

87. F.A. Stevie, T.C. Shane, P.M. Kahora, R. Hull, D. Bahnck, V.C. Kannan, E. David, Surf. Interface Anal. 23, 61 (1995).

88. R. Anderson, S.J. Klepeis, in Mater. Res. Soc. Symp. Proc. $\mathbf{4 8 0}$ (Materials Research Society, Warrendale, PA, 1997), p. 198

89. S.D. Walck, H. Colijn, G. Thompson, Microsc. Microanal. 7, 952 (2001)

90. S. Welz, N. Browning, A. Minor, Microsc. Microanal. 11 (Suppl. 2), 834 (2005)

91. H.C. Floresca, J. Jeon, J.G. Wang, M.J. Kim, Microsc. Microanal. 15, 558 (2009).

92. M. Schaffer, B. Schaffer, Q. Ramasse, Ultramicroscopy 114, 62 (2012).

93. L.A. Giannuzzi, B.W. Kempshall, S.M. Schwarz, J.K. Lomness, B.I. Prenitzer, F.A. Stevie, in Introduction to Focused Ion Beams, L.A. Giannuzzi, F.A. Stevie, Eds. (Springer, New York, 2005), p. 201.

94. T. Kamino, T. Yaguchi, T. Hashimoto, T. Ohnishi, K. Umemura, in Introduction to Focused Ion Beams, L.A. Giannuzzi, F.A. Stevie, Eds. (Springer, New York, 2005), p. 229.

95. L.A. Giannuzzi, Proc. ISTFA 388 (2012).

96. L.A. Giannuzzi, Microsc. Microanal. 18 (Suppl. 2), 632 (2012).

97. L.A. Giannuzzi, Microsc. Microanal. 19 (Suppl. 2), 906 (2013). 
98. R. Salzer, L. Lechner, Microsc. Microanal. 18 (Suppl. 2), 653 (2012). 99. L. Lechner, J. Biskupek, U. Kaiser, Microsc. Microanal. 18, 379 (2012). 100. L. Lechner, U. Kaiser, J. Biskupek, European Patent 2413126A2 (2012). 101. M. Marko, C. Hsieh, R. Schalek, J. Frank, C. Mannella, Nat. Methods 4 215 (2007)

102. H.K. Edwards, M.W. Fay, S.I. Anderson, C.A. Scotchford, D.M. Grant, P.D. Brown, J. Microsc. 234, 16 (2009).

103. A. Rigort, F.J.B. Bäuerlein, E. Villa, M. Eibauer, T. Laugks, W. Baumeister, J. Plitzko, Proc. Natl. Acad. Sci. U.S.A. 109, 4449 (2012)

104. V. Ray, Proc. ISTFA 534 (2004)

105. F. Lacour, N. Courjal, M.-P. Bernai, A. Sabac, C. Bainier, M. Spajer, Opt. Mater. 27, 1421 (2005).

106. E.J.R. Vesseur, R. de Waele, H.J. Lezec, H.A. Atwater, F.J. Garcia de Abajo, A. Polman, Appl. Phys. Lett. 92, 083110 (2008).

107. E. Palacios, L.E. Ocola, A. Joshi-Imre, S. Bauerdick, M. Berse, L. Peto, J. Vac. Sci. Technol. B 28, C6l1 (2010).

108. J.L. Gray, R. Hull, J.A. Floro, J. Appl. Phys. 100, 7 (2006).

109. K. Keskinbora, C. Grévent, U. Eigenthaler, M. Weigand, G. Schütz, ACS Nano 7, 9788 (2013)

110. R. Salzer, H. Stegmann, Microsc. Microanal. 18 (Suppl. 2), 636 (2012)

111. S.R. Marder, J.-L Brédas, J.W. Perry, MRS Bull. 32, 561 (2007).

112. A. Dietzel, R. Berger, H. Loeschner, E. Platzgummer, G. Stengl, W.H. Bruenger, F. Letzkus, Adv. Mater. 15, 1152 (2003).

113. L. Holzer, M. Cantoni, in Nanofabrication Using Focused Ion and Electron Beams, I. Utke, S. Moshkalev, P. Russell, Eds. (Oxford University Press, New York, 2012) pp. 410-435.

114. M.D. Uchic, L. Holzer, B.J. Inkson, E.L. Principe, P. Munroe, MRS Bull. 32 , 408 (2007)

115. P. Kotula, M.R. Keenan, J.R. Michael, Microsc. Microanal. 12, 36 (2006).

116. M. Schaffer, J. Wagner, B. Schaffer, M. Schmied, H. Mulders, Ultramicroscopy 107, 587 (2007).

117. L.A. Giannuzzi, in Proc. SPIE 8378, 83780P-4 (2012).

118. K. Narayan, C.M. Danielson, K. Lagarec, B.C. Lowekamp, P. Coffman, A. Laguerre, M.W. Phaneuf, T.J. Hope, S. Subramaniam, J. Struct. Biol. (2013), doi: 10.1016/j.jsb.2013.11.0008.

119. B. Maco, A. Holtmaat, M. Cantoni, A. Kreshuk, C.N. Straehle, F.A. Hamprecht, G.W. Knott, PLoS One 8, e57405 (2013).

120. L.H.P. Hekking, M.N. Lebbink, D.A.M. de Winter, C.T.W.M. Schneijdenberg, C.M. Brand, B.M. Humbel, A.J. Verkleij, J.A. Post, J. Microsc. 235, 336 (2009). 121. A.J. Bushby, K.M.Y. P'ng, R.D. Young, C. Pinali, C. Knupp, A.J. Quantock, Nat. Protoc. 6, 845 (2011).

122. G.E. Murphy, K. Narayan, B.C. Lowekamp, L.M. Hartnell, J.A.W. Heymann, J. Fu, S. Subramaniam, J. Struct. Biol. 176, 268 (2011).

123. R.D. Holbrook, J.M. Davis, K.C. Scott, C. Szakal, J. Microsc. 246, 143 (2012) 124. M. Lopez-Haro, T. Jiu, P. Bayle-Guillemaud, P.H. Jouneau, F. Chandezon, Nanoscale 5, 10945 (2013).

125. K. Scott, N.W.M. Ritchie, J. Microsc. 233, 331 (2009).

126. P. Lechner, C. Fiorini, A. Longoni, G. Lutz, A. Pahlke, H. Soltau, L. Strüder, ICDD 47, 53 (2004).
127. H. Fraser, D. Klenov, Y.-C. Wang, H. Cheng, N. Zaluzec, Microsc. Microanal. 17 (Suppl. 2), 590 (2011).

128. D. Newbury, N.W.M Ritchie, J. Anal. At. Spectrom. 98, 973 (2013).

129. R.A. Schwarzer, D.P. Field, B.L. Adams, M. Kumar, A.J. Schwartz, in Electron Backscatter Diffraction in Materials Science, A.J. Schwartz, M. Kumar, B.L. Adams, D.P. Field, Eds. (Springer, New York, 2009), pp. 1-20.

130. H. Jaksch, J.P. Martin, Fresenius. J. Anal. Chem. 353, 378 (1995).

131. A. Endo, M. Yamada, S. Kataoka, T. Sano, Y. Inagi, A. Miyaki, Colloids Surf. A 357, 11 (2010)

132. N. Erdman, D.C. Bell, in Low Voltage Electron Microscopy, D.C. Bell, N. Erdman, Eds. (Wiley, United Kingdom, 2013), pp. 41-43.

133. R.J. Young, G.N.A. van Veen, Al Henstra, L. Tuma, in Low Voltage Electron Microscopy, D.C. Bell, N. Erdman, Eds. (Wiley, United Kingdom, 2013), pp. 65-66.

134. T.M. Lillesand, R.W. Kiefer, J.W. Chipman, Remote Sensing and Image Interpretation, 6th ed. (Wiley, New York, 2007).

135. M. Sonka, V. Hlavac, R. Boyle, Image Processing, Analysis and Machine Vision, 4th ed. (Cengage Learning, Stamford, CT, 2014).

136. J. Aloimonos, I. Weiss, A. Bandyopadhyhay, Int. J. Comput. Vis. 1, 333 (1988)

137. E.J. Candès, Int. Cong. Math. 3, 1433 (2006)

138. R. Baraniuk, IEEE Signal Process. Mag. 24, 118 (2007).

139. E.J. Candès, B. Recht, Commun. ACM 55, 112 (2008)

140. J. Romberg, IEEE Signal Process. Mag. 25, 14 (2008).

141. S. Geethanath, H.M. Baek, S.K. Ganji, Y. Ding, E.A. Maher, R.D. Sims, C. Choi, M.A. Lewis, V.D. Kodibagkar, Radiology 262, 985 (2012).

142. M.F. Schiffner, T. Jansen, G. Schmitz, Biomed. Tech. 57 (Suppl. 1), 192 (2012).

143. Z. Saghi, D.J. Holland, R. Leary, A. Falqui, G. Bertoni, A.J. Sederman, L.F. Gladden, P.A. Midgley, Nano Lett. 11, 4666 (2011).

144. D.A.M. de Winter, M.N. Lebbink, D.F. Wiggers de Vries, J.A. Post, M.R. Drury, J. Microsc. 243, 315 (2011).

145. D.A.M. de Winter, G.M. Pennock, J.A. Post, M.R. Drury, Microsc. Microanal 19 (Suppl. 2), 1868 (2013)

146. M.P. Ryan, D.E. Williams, R.J. Cjater, B.M. Hutton, D.S. McPhall, Nature 415, 770 (2002)

147. J. Jiruše, L. Sedláček, M. Rudolf, V. Fridli, F. Oestlund, J. Whitby, Microsc Microanal. 18 (Suppl. 2), 638 (2012).

148. H. Stegmann, H. Dömer, R. Rosenkranz, E. Zschech, Microsc. Microanal 17 (Suppl. 2), 658 (2011)

149. Y. Peng, I. Luxmoore, M.D. Forster, A.G. Cullis, B.J. Inkson, J. Phys. Conf Ser. 126, 012031 (2008)

150. A. Rummei, K. Schock, M. Kemmler, A. Smith, S. Kleindiek, Microelectron. Reliab. 53, 1427 (2013).

151. A. Rigort, F. Bauerlein, T. Laugks, M. Hayles, C. Mathisen, B. Lich R. Morrison, A. Leis, W. Baumeister, J. Plitzko, Microsc. Microanal. 16 (Suppl. 2), $220(2010)$

152. I. Weikusat, D.A.M de Winter, G.M. Pennock, M. Hayles, C.T.W.M Schneijdenberg, M.R. Drury, J. Microsc. 242, 295 (2011).

153. K. Rykaczewski, T. Landin, M. Walker, J.H.J. Scott, K.K. Varanasi, ACS Nano, 6, 9326 (2012)

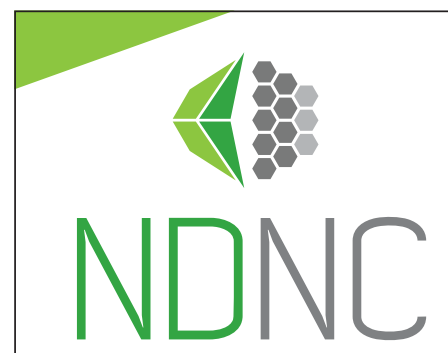

PREREGISTRATION DEADLINEMAY 9, 2014

\section{PREREGISTER AND SAVE!}

\section{New Diamond and Nano Carbons Conference May 25-29, 2014 | Hyatt Regency Chicago | Chicago, Illinois, USA}

\section{SCIENTIFIC PROGRAM}

The five-day Conference will span:

Synthesis, Characterization, Properties, and Applications of Diamond (Including Single Crystal, Micro, Nano and Ultrananocrystalline) and Diamond-like Carbon

- Synthesis, Characterization, Properties, and Applications of Graphene

Synthesis, Characterization, Properties, and Applications of Carbon Nanotube (CNT)

For the full list of topics, visit www.mrs.org/ndnc-2014. 